\title{
ANALISIS KEPADATAN TANAH PADA RUAS JALAN MASUK KEMAKAM GURU CANTUNG KECAMATAN KELUMPANG HULU KABUPATEN KOTABARU
}

\author{
Dina Heldita ${ }^{1)}$ \\ ${ }^{I}$ Program Studi Teknik Sipil Politeknik Kotabaru \\ Jalan Stagen Km. 9,5 Desa Stagen Kabupaten Kotabaru Kalimantan Selatan \\ E-mail: dinaheldita@ymail.com
}

\begin{abstract}
Support for highway planning that must be determined according to the optimal traffic requirements for traffic that is in accordance with its function. Analysis of soil density on the Banian-Sungai Durian road uses a Dynamic Cone Penetrometer (DCP) tool with the aim of finding the CBR value of the soil. The value supported is to get the DCP value, the California Bearing Ratio (CBR) value, and the Land Carrying Capacity (DDT) value. Tests carried out along the $1,550 \mathrm{~m}$ with a width of $4 \mathrm{~m}$. For the point of data collection zigzag per $100 \mathrm{~m}$. The test results show the average value of DCP is $29.32 \mathrm{~mm}$, while the average value of CBR is $5.07 \%$. Design CBR value is $2.24 \%$, with DDT is $4.47 \%$. The CBR value of the design / plan obtained does not meet the standard CBR value requirements that have been set at $6 \%$. It needs to be recompacted on the ground because it does not meet the CBR value standards that have been determined and approved to add road pavement.
\end{abstract}

Keywords: Land density, DCP, Field CBR, Banian Village

\section{PENDAHULUAN}

Daya dukung untuk perencanaan jalan raya yang baik harus ditetapkan sedemikian rupa sehingga jalan yang bersangkutan dapat memberikan pelayanan yang optimal kepada lalu lintas sesuai dengan fungsinya. Menurut Sukirman (1999) kekuatan dan keawetan kontruksi perkerasan jalan sangat ditentukan oleh sifat-sifat daya dukung tanah dasar. Dalam Varian CBR Yang Mewakili Terhadap Uji Kedalaman DCP, CBR merupakan perbandingan antara beban (tegangan) yang diperlukan untuk mencapai harga penetrasi tertentu pada tanah dasar terhadap beban standar. CBR biasa dipergunakan untuk menyatakan standar kekuatan daya dukung tanah relatif. Kekuatan relatif tanah dasar ditentukan dengan uji CBR laboratorium atau uji CBR lapangan untuk mencari nilai CBR yang mewakili lapangan dipergunaka alat DCP. Dengan cara ini suatu percobaan penetrasi (disebut percobaan penetrasi) dipergunakan untuk menilai kekuatan tanah dasar atau bahan lain yang hendak dipakai untuk pembuatan perkerasan, Nilai CBR yang diperoleh kemudian dipakai menentukan tebal lapisan perkerasan yang diperlukan diatas lapisan yang nilai CBR-nya ditentukan Shalahuddin (2012).

\section{METODE PENELITIAN}

\section{Dynamic Cone Penetrometer (DCP)}

Pengujian Dynamic Cone Penetrometer (DCP) dimaksudkan untuk menentukan nilai CBR (California Bearing Ratio) tanah dasar, timbunan, dan atau suatu sistem perkerasan. Pengujian ini akan memberikan data kekuatan tanah sampai kedalaman kurang lebih $70 \mathrm{~cm}$ di bawah permukaan lapisan tanah yang ada atau permukaan tanah dasar. Pengujian ini dilakukan dengan mencatat data masuknya konus yang tertentu dimensi dan sudutnya, ke dalam tanah untuk setiap pukulan dari palu/hammer yang berat dan tinggi jatuh tertentu pula. Pengujian dengan alat DCP ini pada dasarnya sama dengan Cone Penetrometer $(\mathrm{CP})$ yaitu samasama mencari nilai CBR dari suatu lapisan tanah langsung di lapangan. Hanya saja pada alat CP dilengkapi dengan poving ring dan arloji pembacaan, sedangkan pada DCP adalah melalui ukuran (satuan) dengan menggunakan mistar 
percobaan dengan alat CP digunakan untuk mengetahui CBR tanah asli, sedangkan percobaan dengan alat DCP ini bisa untuk mendapat kekuatan tanah timbunan atau tanah asli pada pembuatan badan jalan, alat ini dipakai pada pekerjaan tanah karena mudah dipindahkan ke semua titik yang diperlukan tetapi letak lapisan yang diperiksa tidak sedalam pemeriksaan tanah dengan alat sondir. Pengujian dilaksanakan dengan mencatat jumlah pukulan (blow) dan penetrasi dari konus (kerucut logam) yang tertanam pada tanah/lapisan pondasi karena pengaruh penumbuk kemudian dengan menggunakan grafik dan rumus, pembacaan penetrometer diubah menjadi pembacaan yang setara dengan nilai CBR.

Alat DCP terdiri atas tangkai baja yang di bagian ujung dipasang konus baja dengan ukuran dan sudut tertentu. Dan dibagian atas dilengkapi dengan batang pengarah jatuh palu penumbuk.Metode DCP ini adalah cara pengujian kekuatan lapisan perkerasan jalan (tanah dasar, pondasi bahan berbutir) yang relative cepat yaitu dengan menekan ujung konus yang ditimbulkan oleh pukulan palu dengan beban dan tinggi jatuh tertentu menerus sampai kedalam.

Untuk memperkirakan nilai CBR tanah atau bahan granular dapat menggunakan beberapa metode, namun yang cukup akurat dan paling murah sampai saat ini adalah dengan alat penetrasi konus dinamis atau dikenal dengan nama dynamic cone penetrometer (DCP). Disamping itu DCP adalah salah satu cara pengujian tanpa merusak Non Destructive Testing (NDT), yang digunakan untuk lapis pondasi batu pecah, pondasi bawah, stabilisasi tanah dengan semen atau kapur dan tanah dasar.

\section{Cara Uji CBR dengan Dynamic Cone Penetrometer (DCP)}

Cara uji CBR dengan Dinamic Cone Penetrometer (DCP) menggunakan "Pedoman Konstruksi Bangunan dan Rekayasa Sipil" yang di terbitkan oleh Departemen Pekerjaan Umum Nomor 8 Tahun 2007. Pedoman ini menetapkan cara uji kekuatan atau daya dukung (CBR) di lapangan secara cepat dengan menggunakan alat penetrometer konus dinamis (Dynamic Cone Penetrometer, DCP).

\section{Istilah dan Definisi}

Istilah dan definisi yang digunakan dalam pedoman ini adalah sebagai berikut:

a. Alat penetrometer konus dinamis (Dynamic Cone Penetrometer,DCP)Suatu alat yang terdiri dari tiga bagian utama, yang satu sama lain harus disambung sehingga cukup kaku.

b. California Bearing Ratio (CBR)

Rasio beban penetrasi suatu bahan dengan piston standar yang mempunyai luas 1935 mm (3 inci persegi) terhadap beban standar dengan kedalaman dan kecepatan penetrasi 1,27 $\mathrm{mm} /$ menit $(0,05$ inci per menit).

c. Konus

Logam terbuat dari baja keras, yang bagian ujungnya berbentuk kerucut dengan sudut $30^{\circ}$ untuk bahan granular. Untuk hal-hal khusus seperti tanah berbutir halus digunakan kerucut dengan sudut $60^{\circ}$, penggunaan sudut konus akan menentukan pula rumus atau grafik hubungan nilai DCP dan CBR yang harus digunakan untuk menentukan nilai CBR.

d. Lubang uji (test pits)

Pengujian dengan membuat lubang uji yang umumnya berukuran $60 \mathrm{~cm}$ x $60 \mathrm{~cm}$ untuk mengetahui jenis lapisan perkerasan sampai kedalaman tertentu atau tanah dasar.

\section{Peralatan dan Personil}

Alat penetrometer konus dinamis (DCP) terdiri dari tiga bagian utama yang satu sama lain harus disambung sehingga cukup kaku, seperti telihat pada Gambar 1.

a. Peralatan utama

1. Bagian atas

a. Pemegang.

b. Batang bagian atas diameter $16 \mathrm{~mm}$, tinggijatuh setinggi $575 \mathrm{~mm}$.

2. Penumbuk berbentuk silinder berlubang, berat 8 $\mathrm{kg}$. Bagian tengah

a. Landasan penahan penumbuk terbuat dari baja.

b. Cincin peredam kejut.

c. Pegangan untuk pelindung mistar penunjuk kedalaman. 

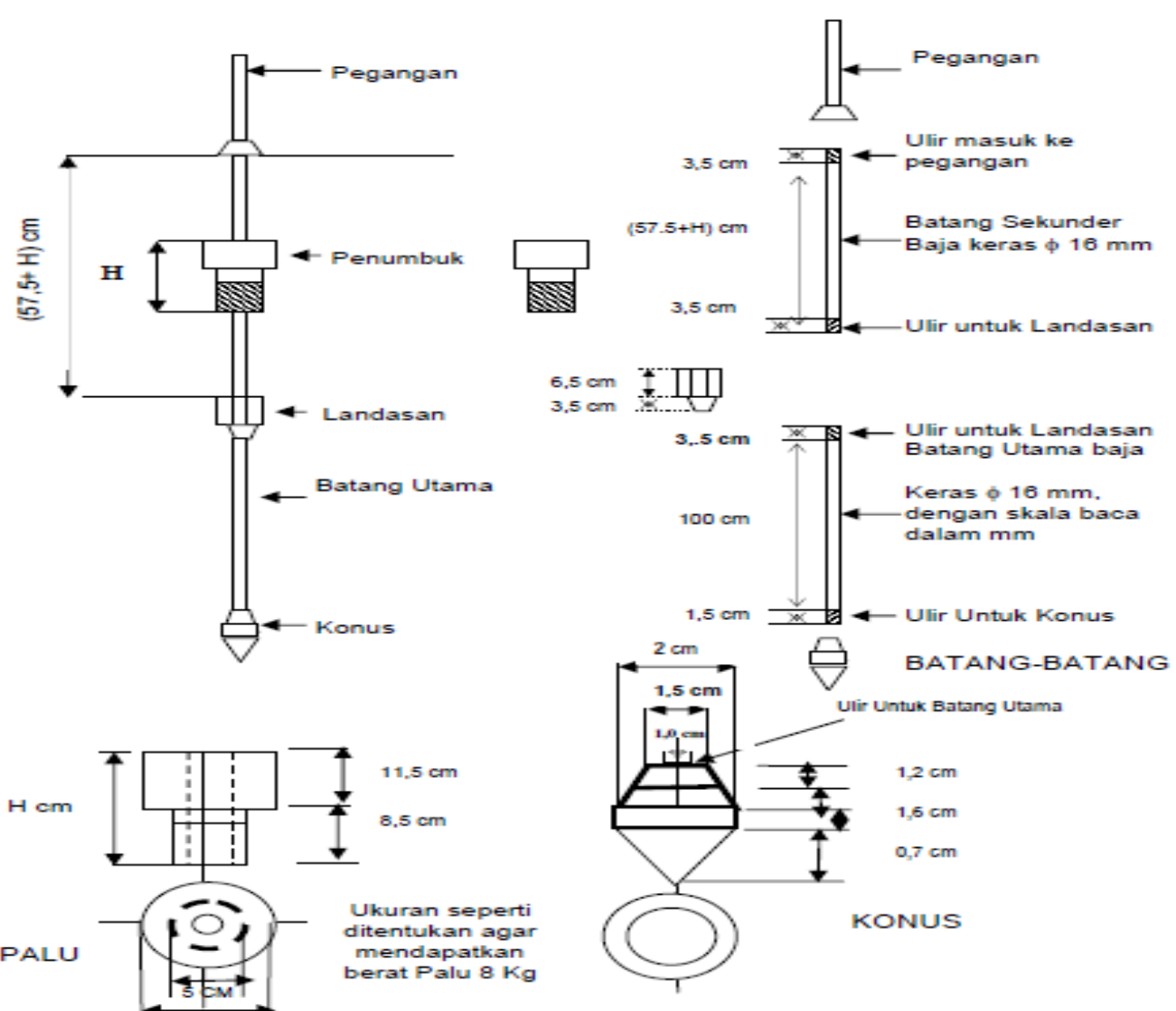

Gambar 1. Bagian dari Penetrometer Konus Dinamis (DCP)

3. Bagian bawah

a. Batang bagian bawah, panjang $90 \mathrm{~cm}$, diameter $16 \mathrm{~mm}$.

b. Batang penyambung, panjang antara $40 \mathrm{~cm}$ sampai dengan $50 \mathrm{~cm}$, diameter $16 \mathrm{~mm}$ dengan ulir dalam di bagian ujung yang satu dan ulir luar di ujung lainnya.

c. Mistar berskala, panjang 1 meter, terbuat dari plat baja.

d. Konus terbuat dari baja keras berbentuk kerucut di bagian ujung, diameter $20 \mathrm{~mm}$, sudut $60^{\circ}$ atau $30^{\circ}$.

e. Cincin pengaku.

b. Alat bantu

Peralatan bantu adalah cangkul, sekop, blincong, pahat, linggis, palu, core drill apabila pengujian pada lapisan perkerasan beraspal, alat ukur panjang/pita ukur yang bisa dikunci, kunci pas, formulir lapangan dan alat tulis.

c. Personil
Pengujian DCP memerlukan 3 orang teknisi, yaitu:

1. Satu orang memegang peralatan yang sudah terpasang dengan tegak;

2. Satu orang untuk mengangkat dan menjatuhkan penumbuk;

3. Satu orang untuk mencatat hasil.

\section{Persiapan Alat dan Lokasi Pengujian}

Persiapan alat dan lokasi pengujian, sebagai berikut:

a. Sambungkan seluruh bagian peralatan dan pastikan bahwa sambungan batang atas dengan landasan serta batang bawah dan kerucut baja sudah tersambung dengan kokoh.

b. Tentukan titik pengujian, catat Sta./Km., kupas dan ratakan permukaan yang akan diuji.

c. Buat lubang uji pada bahan perkerasan yang beraspal, sehingga didapat lapisan tanah dasar.

d. Ukur ketebalan setiap bahan perkerasan yang ada dan dicatat. 


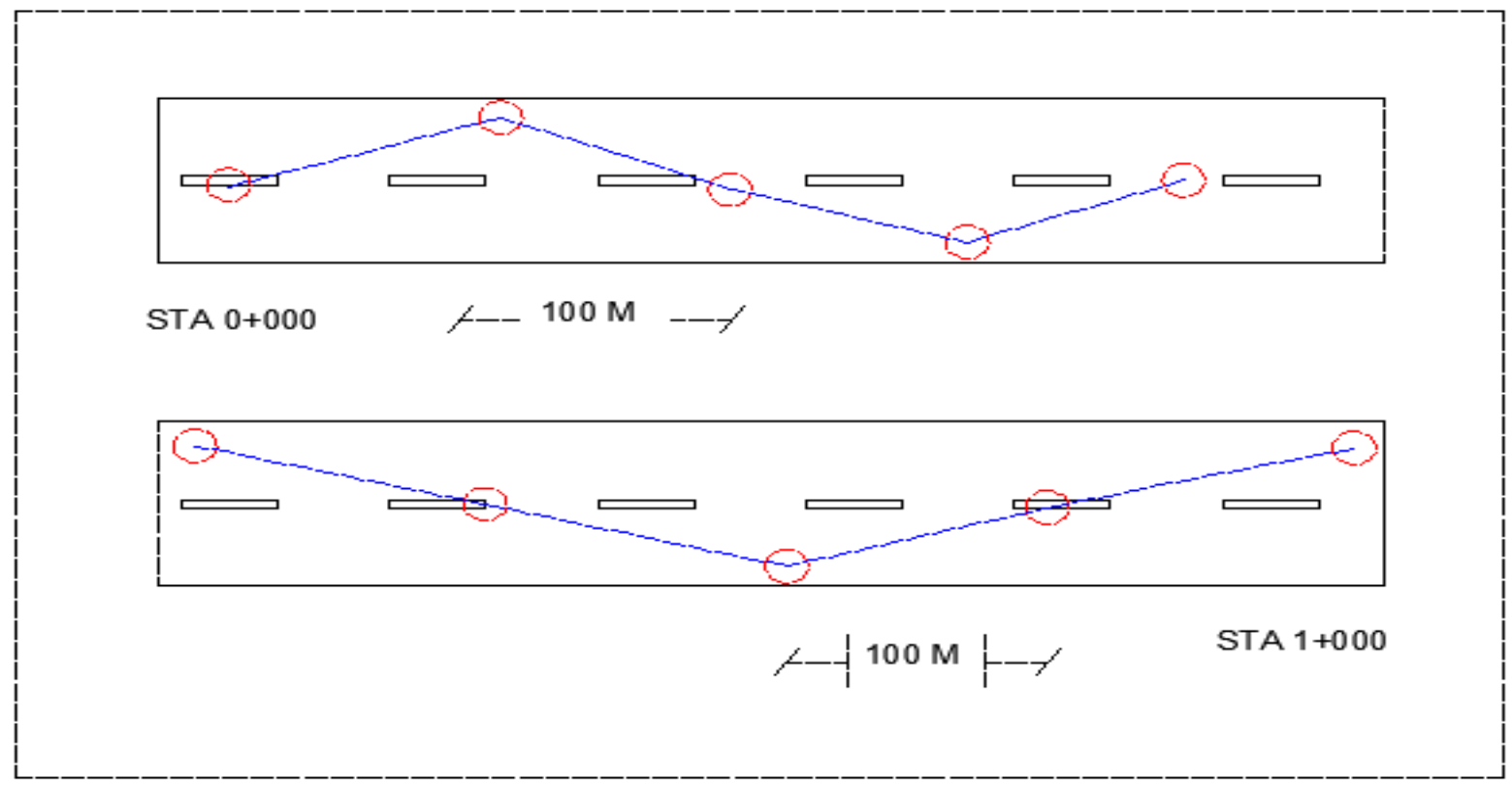

Gambar 2. Lokasi Pengujian dengan Alat DCP untuk Perbaikan

Lokasi pengujian dengan alat DCP ditentukan sesuai dengan keperluan jalan yang akan diuji, untuk lebih jelasnya dapat dilihat dalam Gambar sebagai berikut:

a. Perbaikan dengan Pelebaran

Lokasi pengujian menggunakan alat DCP untuk keperluan perbaikan dengan pelebaran dilaksanakan pada tepi luar perkerasan lama dan posisi DCP tidak mengganggu perkerasan lama, seperti dalam Gambar 2.

dengan Pelebaran (Tampak Atas)

b. Pembangunan jalan baru atau rekonstruksi

Lokasi pengujian dengan alat DCP untuk keperluan pembangunan jalan baru atau rekonstruksi dilaksanakan pada center line. Overlay jalan aspal, akan tetapi didesain dengan basis data CBR

Lokasi pengujian dengan alat DCP untuk keperluan overlay jalan aspal dilakukan pada wheel track kendaraan bermotor roda empat atau lebih dengan ketentuan perkerasan aspal digali sampai tepi bawah lapisan beraspal dan posisi alat DCP diletakkan di atas lapisan yang tidak beraspal (dapat berupa base atau subbase tergantung jenis lapis perkerasan).

\section{Cara Pengujian}

a. Letakkan alat DCP pada titik uji di atas lapisan yang akan diuji. b. Pegang alat yang sudah terpasang pada posisi tegak lurus di atas dasar yang rata dan stabil, kemudian catat pembacaan awal pada mistar pengukur kedalaman.

c. Mencatat jumlah tumbukan:

1. Angkat penumbuk pada tangkai bagian atas dengan hati-hati sehingga menyentuh batas pegangan.

2. Lepaskan penumbuk sehingga jatuh bebas dan tertahan pada landasan.

3. Lakukan langkah-langkah pada di atas, catat jumlah tumbukan dan kedalaman pada formulir DCP, sesuai ketentuan-ketentuan sebagai berikut:

a. Untuk lapis fondasi bawah atau tanah dasar yang terdiri dari bahan yang tidak keras maka pembacaan kedalaman sudah cukup untuk setiap 1 tumbukan atau 2 tumbukan.

b. Untuk lapis fondasi yang terbuat dari bahan berbutir yang cukup keras, maka harus dilakukan pembacaan kedalaman pada setiap 5 tumbukan sampai dengan 10 tumbukan.

4. Hentikan pengujian apabila kecepatan penetrasi kurang dari $1 \mathrm{~mm} / 3$ tumbukan. Selanjutnya lakukan pengeboran atau penggalian pada titik tersebut sampai mencapai bagian yang dapat diuji kembali. 
d. Pengujian per titik, dilakukan minimum dua kali dengan jarak $20 \mathrm{~cm}$ dari titik uji satu ke titik uji lainnya. Langkah-langkah setelah pengujian:

1. Siapkan peralatan agar dapat diangkat atau dicabut ke atas.

2. Angkat penumbuk dan pukulkan beberapa kali dengan arah ke atas sehingga menyentuh pegangan dan tangkai bawah terangkat ke atas permukaan tanah.

3. Lepaskan bagian-bagian yang tersambung secara hati-hati, bersihkan alat dari kotoran dan simpan pada tempatnya. Tutup kembali lubang uji setelah pengujian

\section{Hubungan (korelasi) Nilai CBR-DCP}

Dari data, didapat nilai DCP yang diambil adalah jumlah rata-rata dari penetrasi pukulan.Dari nilai DCP yang ada, dapat dicari nilai CBR yng ada. Semakin kecil nilai presentasi DCP, maka makin besar nilai CBR yang terjadi, dan sebaliknya semakin besar nilai presentasi DCP, maka semakin kecil nilai CBR yang terjadi. Nilai korelasi yang terjadi didapat dari beberapa percobaan yang sdah dilakukan oleh beberapa peneliti. Hubungan tersebut diperlihatkan dalam Gambar 3.

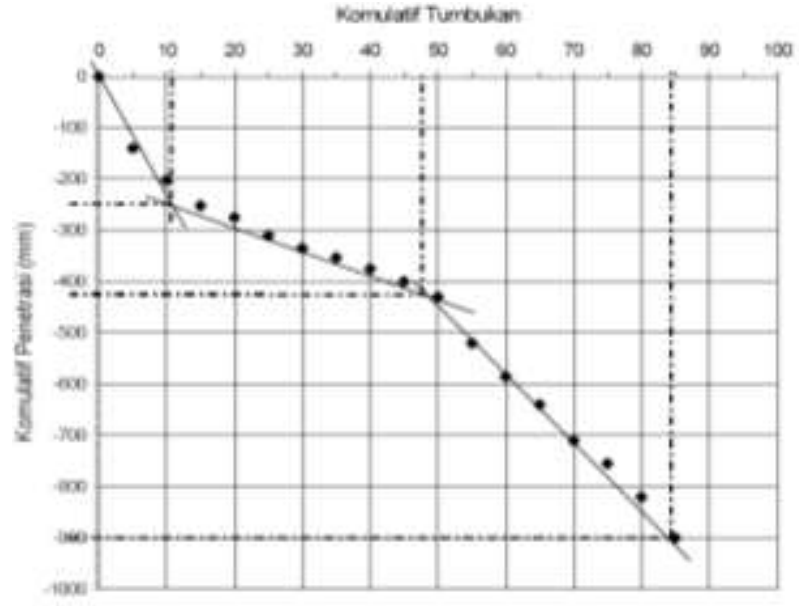

Gambar 3. Hubungan Kumulatif Tumbukan dan Kumulatif Penetrasi

Adapun perhitungan niai CBR rencana ada prosedur-prosedur yang harus diperhatikan. prosedurnya adalah sebagai berikut:

1. Tentukan Nilai CBR terendah.

2. Nilai CBR yang sama atau lebih besar dari masing-masing nilai CBR disusun secara tabel mulai dari nilai CBR terkecil sampai terbesar, seperti pada tabel 2 .
3. Angka terbanyak diberi nilai $100 \%$, angka yang lain merupaka persentase dari $100 \%$ seperi pada grafik pada gambar 4.26

4. Dibuat grafik hubungan antara harga CBR dan persentase jumlah tadi

5. Nilai CBR rencana adalah nilai pada keadaan $90 \%$.

\section{HASIL DAN PEMBAHASAN}

Setiap segmen mempunyai satu nilai CBR yang mewakili daya dukung tanah dasar dan dipergunakan untuk perencanaan lapisan perkerasan dari segmen tersebut. Nilai CBR segmen dapat ditentukan menggunakan cara grafis.

Adapun nilai CBR rata-rata setiap segmen dari hasil pengujian di lapangan dapat dilihat dalam Tabel 1 dan 2. Berdasarkan hasil pengolaan data DCP diperoleh nilai CBR rata-rata mulai STA 0+000 sampai STA $1+550$.

a. STA $0+000=3,43 \%$

b. STA $0+300=4,34 \%$

c. STA $0+800=1,76 \%$

d. STA $1+200=3,09 \%$

e. STA $1+500=1,84 \%$

Dari tabel 2 nilai CBR yang digunakan untuk mengetahui nilai CBR rencana atau CBR desain adalah CBR pada kondisi $90 \%$. Adapun nilai CBR 90\% dapat dilihat pada Grafik dalam Gambar 4:

\section{KESIMPULAN}

Dalam analisis kepadatan tanah Menggunakan alat DCP di jalan Desa Karang Payau Kecamatan kelumpang Hulu yang dianalisis penulis adalah untuk nilai standar CBR desain/rencana yaitu $6 \%$. Dikarenakan nilai CBR desain/rencana belum memenuhi standar CBR yang sudah ditetapkan yaitu 6\% sehingga perlu dilakukan pemadatan kembali pada tanah dasar.

Dengan mendapatkan data hasil perhitungan CBR tanah dasar atau CBR desain sebesar 5,07 secara Grafis maka didapat nilai DDT yaitu $4,74 \%$. 
Tabel 1. Hasil Pengujian DCP

\begin{tabular}{|c|c|c|c|}
\hline \multirow{2}{*}{$\frac{\text { Titik }}{1}$} & \multicolumn{2}{|c|}{ STA } & \multirow{2}{*}{$\begin{array}{c}\begin{array}{c}\text { Rata-rata Nilai } \\
\text { CBR }\end{array} \\
3,43\end{array}$} \\
\hline & STA & $0+000$ & \\
\hline 2 & STA & $0+300$ & 4,34 \\
\hline 3 & STA & $0+800$ & 1,76 \\
\hline 4 & STA & $1+200$ & 3,09 \\
\hline 5 & STA & $1+500$ & 1,84 \\
\hline 6 & STA & $4+650$ & 23,09 \\
\hline 7 & STA & $4+900$ & 1,74 \\
\hline 8 & STA & $5+200$ & 14,13 \\
\hline 9 & STA & $5+500$ & 1,59 \\
\hline 10 & STA & $5+800$ & 22,81 \\
\hline 11 & STA & $6+100$ & 1,22 \\
\hline 12 & STA & $6+400$ & 1,85 \\
\hline 13 & STA & $7+700$ & 1,48 \\
\hline 14 & STA & $7+100$ & 2,42 \\
\hline 15 & STA & $7+400$ & 1,24 \\
\hline 16 & STA & $7+700$ & 2,30 \\
\hline 17 & STA & $8+000$ & 1,54 \\
\hline 18 & STA & $8+300$ & 0,49 \\
\hline 19 & STA & $8+600$ & 1,60 \\
\hline 20 & STA & $8+900$ & 1,47 \\
\hline 21 & STA & $9+200$ & 1,37 \\
\hline 22 & STA & $9+500$ & 1,76 \\
\hline 23 & STA & $9+800$ & 23,73 \\
\hline 24 & STA & $10+000$ & 1,45 \\
\hline & $\mathrm{R}$ Rat & & 5,07 \\
\hline
\end{tabular}

Tabel 2. Data Nilai CBR

\begin{tabular}{|c|c|c|}
\hline \multirow{2}{*}{ CBR } & $\begin{array}{c}\text { Jumlah yang } \\
\text { sama atau }\end{array}$ & \multirow{2}{*}{$\begin{array}{l}\text { Persen yang sama } \\
\text { atau lebih besar }(\%)\end{array}$} \\
\hline & lebih besar & \\
\hline 0,49 & 24 & $100 \%$ \\
\hline 1,22 & 23 & $96 \%$ \\
\hline 1,24 & 22 & $92 \%$ \\
\hline 1,37 & 21 & $88 \%$ \\
\hline 1,45 & 20 & $83 \%$ \\
\hline 1,47 & 19 & $79 \%$ \\
\hline 1,48 & 18 & $75 \%$ \\
\hline 1,54 & 17 & $71 \%$ \\
\hline 1,59 & 16 & $67 \%$ \\
\hline 1,60 & 15 & $63 \%$ \\
\hline 1,74 & 14 & $58 \%$ \\
\hline 1,76 & 13 & $54 \%$ \\
\hline 1,76 & 12 & $50 \%$ \\
\hline 1,84 & 11 & $46 \%$ \\
\hline 1,85 & 10 & $42 \%$ \\
\hline 2,30 & 9 & $38 \%$ \\
\hline 2,42 & 8 & $33 \%$ \\
\hline 3,09 & 7 & $29 \%$ \\
\hline 3,43 & 6 & $25 \%$ \\
\hline 4,34 & 5 & $21 \%$ \\
\hline 14,13 & 4 & $17 \%$ \\
\hline 22,81 & 3 & $13 \%$ \\
\hline 23,09 & 2 & $8 \%$ \\
\hline 23,73 & 1 & $4 \%$ \\
\hline \multicolumn{3}{|l|}{121,74} \\
\hline 5,07 & rata-rata & \\
\hline
\end{tabular}




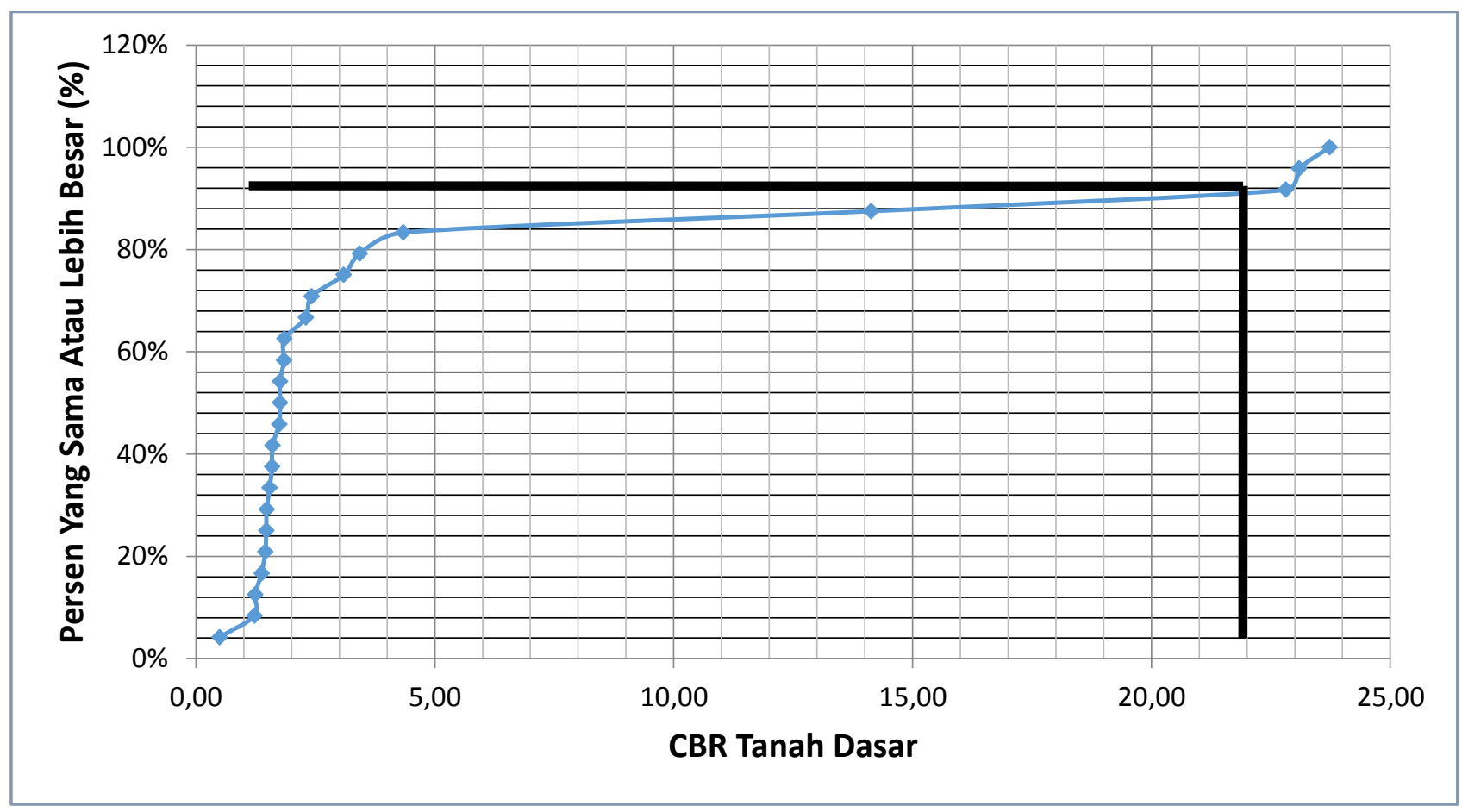

Gambar 4. Grafik Penentu CBR 90\%

\section{DAFTAR PUSTAKA}

SNI 03-4267, Pedoman Cara Uji CBR Dengan Dynamic Cone Penetrometer (DCP), Departemen Pekerjaan Umum 1999.

Sukirman, Silvia. 1999. Perkerasan Lentur Jalan Raya. Nova, Bandung.

Sylviana, 2013. Pengukuran Nilai California Bearing Ratio (CBR) Lapis Perkerasan Aspal Dengan Alat Dynamic Cone Penetrometer (DCP). Universitas Islam 45 Bekasi: Jurusan Teknik Sipil. 